ScIDice

\section{Association Of Age and Gender Distribution of Patients Undergoing Diastema Closure using Direct Composite - A Retrospective Analysis}

Research Article

S.G. Vishnu Prasanna ${ }^{1}$, Subash Sharma 2 , S.P. Saravana Dinesh ${ }^{3}$

${ }^{1}$ Department of Conservative Dentistry and Endodontics, Saveetha Dental College and Hospitals, Saveetha Institute of Medical and Technical Sciences, Saveetha University, Chennai, India.

${ }^{2}$ Reader, Department of Conservative Dentistry and Endodontics, Saveetha Dental College and Hospitals, Saveetha Institute of Medical and Technical Sciences, Saveetha University, Chennai, 600077, India.

${ }^{3}$ Professor and Admin Head, Department of Orthodontics and Dentofacial Orthopedics, Saveetha Dental College and Hospitals, Saveetha Institute of Medical and Technical Sciences, Saveetha University, Chennai, 600077, India.

\title{
Abstract
}

To identify the clinical cases of patients undergoing diastema closure with direct composite in specific age group and gender. Diastema is defined that spaces more than $0.5 \mathrm{~mm}$ between the proximal surfaces of adjacent teeth. The continuing presence of diastema between Maxillary central incisors in adults is often considered as an esthetic or malocclusion problem. Diastemas can be closed by orthodontically, restoratively and also with prosthodontics. Evaluation of patients who reported to Saveetha dental hospital for diastema closure using direct composite. Results were statistically analysed with SPSS software. From the results obtained in the study, young aged adults were more common $(70 \%)$ and males $(62 \%)$ were more common to undergo diastema closure using direct composite. Central incisors more commonly had diastema, young aged males reported with higher incidence for diastema closure with direct composite. There was no significant difference between age group, gender and diastema closure.

Keywords: Age; Gender; Diastema Closure; Direct Composite.

\section{Introduction}

Diastema is defined that spaces more than $0.5 \mathrm{~mm}$ between the proximal surfaces of adjacent teeth [1]. The continuing presence of diastema between the maxillary central incisors in adults is often considered as an aesthetic or malocclusion problem [2]. It was reported that maxilla has higher prevalence of midline diastema more than mandible [3]. Midline diastema has multifactorial etiology which involves labial frenulum, microdontia, peg shaped lateral incisors, habits such as thumb sucking, tongue thrusting and other genetic disorders [4]. Dental caries is the most common cause for the loss of enamel in a clinical situation. Dental caries are easily detectable and reversible at an early stage. Once the incipient lesion proceeds to cavitation, the condition becomes irreversible [5]. Dental caries in incisal edges and proximal sides of anterior teeth can lead to loss of tooth structure leading to spacing. The frequent causes of dental trauma are usually falls, traffic accidents, fights and sports injuries [6]. Dental trauma to the permanent dentition can lead to clinical complications and its management may considerably challenge a practitioner [7]. Trauma to anterior teeth may lead to fracture to incisal region leading to restoration. Dental erosion is defined as the loss of tooth structure due to chemical process that does not involve bacteria [8]. Options to resolvediastemas involve various specialties - orthodontics, restorative and prosthodontics, it is appreciable that restorative approach is the simplest, fastest, most predictable and lowest solution [9]. But also handling composite free hands requires skillful practice. Also one of the difficulties encountered in closing diastema without creating blacks triangle [10]. Direct composite resins in diastema closure cases allow dentist and patient complete control in formation of natural smile [11]. Recent aesthetic composite resin materials have similar physical and mechanical properties to that of the natural tooth and pose an appearance like natural dentin and enamel [12]. Shortcomings of composite restorations in cervical areas have been associated with stress generation on the tooth restoration interface, as a consequence of polymerization shrinkage, and tensile stress caused by

\section{*Corresponding Author:}

Subash Sharma,

Reader, Department of Conservative Dentistry and Endodontics, Saveetha Dental College and Hospitals, Saveetha Institute of Medical and Technical Sciences, Saveetha University, Chennai, 600077, India.

E-mail: subashsharma@saveetha.com

Received: October 07, 2020

Accepted: November 22, 2020

Published: November 27, 2020

Citation: S.G. Vishnu Prasanna, Subash Sharma, S.P. Saravana Dinesh. Association Of Age and Gender Distribution of Patients Undergoing Diastema Closure using Direct Composite - A Retrospective Analysis. Int J Dentistry Oral Sci. 2020;7(11):1144-1147. doi: http://dx.doi.org/10.19070/2377-8075-20000227

Copyright: Subash Sharma 2020 . This is an open-access article distributed under the terms of the Creative Commons Attribution License, which permits unrestricted use, distribution and reproduction in any medium, provided the original author and source are credited. 
oblique occlusal loading [13]. A surgeon is always cautious in removing all the remnants of the linings of the pathological lesion or will be very careful in inspecting its margins after removing it [14].

The other option for closing diastema in restorative dentistry is veneering. A veneer is defined as a thin sheet of material placed on the front surface of the tooth, used for aesthetic purposes and protection. It is usually a thin layer of restorative material replacing the enamel. Veneers are usually the material of choice for a conservative, esthetic approach as they are tooth coloured restorations in order to give the patient a perfect smile [15]. It has both advantages and disadvantages, advantage is that it produces good aesthetics and disadvantage is that it is more expensive for the patient. This study was conducted to know the distribution of clinical cases of patients undergoing diastema closure using direct composite with different age groups, gender and teeth number.

\section{Materials and Methods}

\section{Study design and setting}

The study setting is university based single centered study. A retrospective study was conducted on 42 patients who visited a Private Dental College with an aesthetic complaint, diastema closure was done using direct composite for these patients. Thus the population includes patients who underwent diastema closure using direct composite. The advantage of this study was the flexible data that could be obtained immediately and less expensively. The drawback of this study is that there were geographic limitations and the people involved were from an isolated population. The internal validity of the study was carried out by analysing the age and gender of patients who require diastema closure using direct composite. The external validity was determined by the type of composite used.

\section{Data collection}

The inclusion criteria was patients requiring diastema closure using direct composite. The exclusion criteria was patients who didn't require treatment of diastema closure using direct composite. The patient records were reviewed and analysed between June 2019 and March 2020 and the details of patients who had undergone diastema closure using direct composite was noted. All available data was included to minimise sampling bias. Cross verification of details were done with the help of photographs. Patients of all age groups were included in this study. The data of age and gender of patients who underwent diastema closure using direct composite was tabulated. Incomplete and censored data was excluded. Data was entered in a methodical manner. Data was recorded and tabulated on Excel.

\section{Statistical Analysis}

After Excel tabulation, the data was exported to IBM SPSS software [Version 20: IBM Corporation NY USA]. Descriptive statistics were used to calculate correlation between age and gender of patients who underwent direct veneering. The dependent variable was the treatment done which is direct veneering. The independent variables were age and gender. Pearson chi square test was done to statistically analyze the data. Pearson chi square test was used to identify any significant level of variation of association the significance level was set at 0.05 .

\section{Ethical Approval}

The ethical approval for the retrospective study was obtained from the university (SDC/SIHEC/2020/DIASDATA/0619-0320).

\section{Results and Discussion}

From the results obtained in the study, we come to know that young aged males had the highest prevalence for undergoing diastema closure using direct composite. Midline diastema was recorded more commonly and therefore central incisors were affected more commonly and underwent diastema closure using direct composite. The advantages of study were the availability of data and history of the patients. The limitations of the study were the data available was not location specific and belonged to different ethnicities.

According to Bora et al, the study reported that at one year recall, there were no sensitivities, discolouration or fractures were detected on teeth and restorations. Direct composite resins seemed to be highly aesthetic [4]. Prabhu et al reported that $62 \%$ of the restorations in the study had no noticeable colour difference with that of adjacent teeth, and gingival health indicated sample was without any signs of inflammations [16]. Diana at al reported that more than $90 \%$ of graded restorations were categorised as clinically good. A correlation between those rated "clinically sufficient" or worse and the follow up period was observed [17]. Samara et al reported that most of the patients were female $(66.7 \%)$, of all the restorations placed $60 \%$ were first time placements, while $40 \%$ of them were replacements [18].

Figure 1. The bar graph represents frequency distribution of patients based on different age groups. $\mathrm{X}$ axis represents the patients undergoing direct veneering using composite and $\mathrm{Y}$ axis represents the number of patients undergoing diastemaclosure. Young aged adults(18-35 yrs) 76\% were more commonly reported for diastema closure using direct composite.

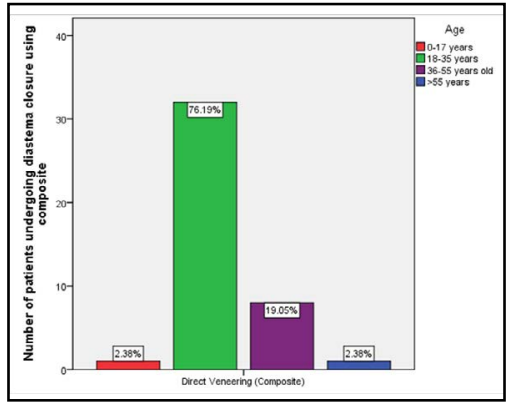


Figure 2. The bar graph represents the frequency distribution of patients based on gender. $\mathrm{X}$ axis represents the gender of the patients and $\mathrm{Y}$ axis represents the number of patients underwent direct veneering. Graph depicts that males were more common to undergo diastema closure $(47.62 \%)$.

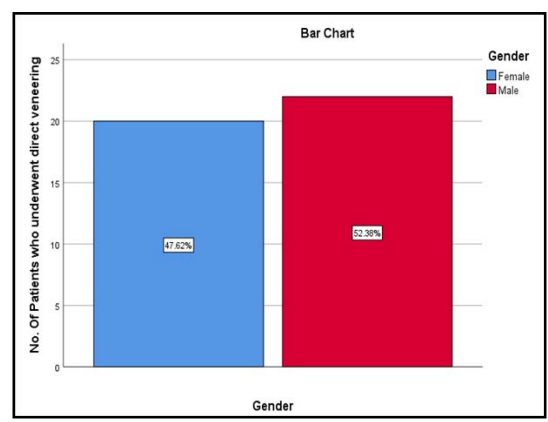

Figure 3. The bar graph represents the type of teeth involved in diastema closure. $X$ axis represents the type of teeth involved and the $\mathrm{Y}$ axis represents the number of patients undergoing diastema closure, Central incisors (Green),Lateral Incisors (Red) and Canines (blue). The graph depicts that central incisors(47\%) were more common to undergo diastema closure using direct composite.

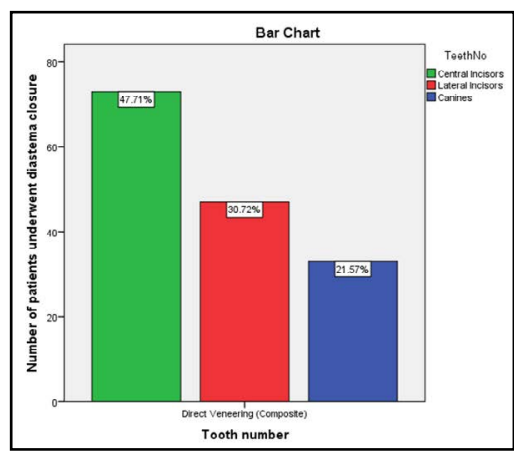

Table 1. Shows Pearson chi square analysis of patients who underwent direct veneering using composite. Pearson chi square value is 23.825 and $P$ value is 0.356 . Thus $P$ value $>0.05$, non-significant association.

\begin{tabular}{|c|c|c|c|}
\hline Statistical analysis & Value & df & Asymptotic Significance [2-sided] \\
\hline Pearson Chi-Square & 23.825 & 22 & 0.356 \\
\hline Likelihood ratio & 31.762 & 22 & 0.082 \\
\hline N of Valid Cases & 42 & & \\
\hline
\end{tabular}

Figure 4. Bar graph represents the association of age and gender of patients undergoing diastema closure using direct composite. $\mathrm{X}$ axis represents the association of age and gender of patients and $\mathrm{Y}$ axis represents the number of patients undergoing diastema closure using direct composite.Pearson's Chi square value $=23,825, \mathrm{df}=22, \mathrm{p}$ value $0.356(>0.05$ ) not statistically significant. Patients in the age group of 18-35 Years and males were more commonly involved in diastema closure.

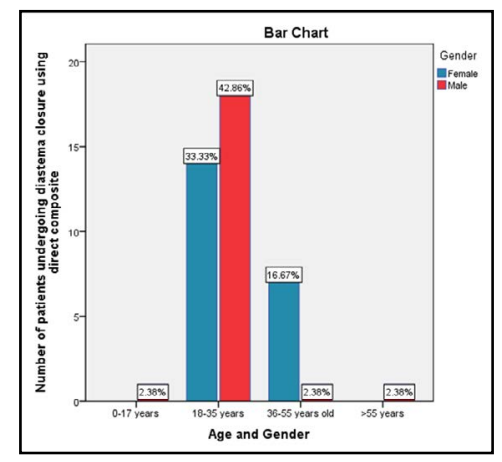

According to Ramamoorthi et al, the study results showed that group Endoactivator resulted in significantly less postoperative pain and analgesics intake than group Endodontic needle [19]. Ramanathan et al reported that there was a no significant difference at 5 and $7 \mathrm{~mm}$ and at 1 and $3 \mathrm{~mm}$ there was significant difference. Mtwo has removed less amount of dentin removal when compared to ProTaper Universal and Pro'Taper Next system at 1 and $3 \mathrm{~mm}$ [20]. Siddique et al reported that Presence of PCA was detected in group $1(\mathrm{CHX}+\mathrm{NaOCl})$, group $2(\mathrm{CHX}+$ neem) and group $3(\mathrm{CHX}+$ tulsi) in all the sensitive methods employed [21]. Rajakeerthi et al reported that among the natural products other than milk, propolis, coconut water, green tea extract, egg white, green tea extract, Aloe Vera gel, pomegranate juice, salvia officinalis followed by dragon blood sap (Croton Lechleri) were recommended based on the cell viability and its longevity [22]. 
Noor et al reported that chlorhexidine has a wide range of activity against both gram positive and gram negative bacteria. It is also used as an irrigant in root canal treatment. In rare cases chlorhexidine may cause allergic reactions [23]. Kavalipurapu et al reported that there was a significant rise in the relative levels of MMP3-mRNA when compared with negative control at 1, 2, and 3 hrs interval [24]. Janani et al reported that the diagnostic accuracy was high with dental pulse oximeter followed by cold, heat and the least was electric pulp tester in different pulpal conditions [24, 25]. Manohar et al., reported that the knowledge level among the study participants was moderately satisfying. However, the need for more education of the dentists with regard to the intracanal medicaments was perceived [26].

\section{Conclusion}

Within the limitations of this study, Central incisors more commonly had diastema, young aged males reported with higher incidence of diastema closure with direct composite. There was no significant difference between age group, gender and diastema closure.

\section{Acknowledgement}

The study was supported by Saveetha dental College and Hospital who provided insights and expertise that greatly assisted the study. We would also like to thank the reviewers of the article for their insights.

\section{References}

[1]. Keene HJ. Distribution of diastemas in the dentition of man. American Journal of Physical Anthropology. 1963 Dec;21(4):437-41.

[2]. Adams CP. The relation of spacing of the upper central incisors to abnormal labial frenum and other features of the dento-facial complex. Dent Pract Dent Rec. 1954;74:72-86.

[3]. Kaimenyi JT. Occurrence of midline diastema and frenum attachments amongst school children in Nairobi, Kenya. Indian J Dent Res. 1998 Apr;9(2):67-71.PubmedPMID: 10530193.

[4]. Korkut B, Yanikoglu F, Tagtekin D. Direct Midline Diastema Closure with Composite Layering Technique: A One-Year Follow-Up. Case Rep Dent. 2016 Jan 6;2016:6810984.PubmedPMID: 26881147.

[5]. Rajendran R, Kunjusankaran RN, Sandhya R, Anilkumar A, Santhosh R, Patil SR. Comparative Evaluation of Remineralizing Potential of a Paste Containing Bioactive Glass and a Topical Cream Containing Casein Phosphopeptide-Amorphous Calcium Phosphate: An in Vitro Study. PesquisaBrasileiraemOdontopediatria e ClínicaIntegrada. 2019;19.

[6]. Jose J, P. A, Subbaiyan H. Different Treatment Modalities followed by Dental Practitioners for Ellis Class 2 Fracture - A Questionnaire-based Survey [Internet]. The Open Dentistry Journal. 2020;14:59-65.

[7]. Kumar D, Antony S. Calcified Canal and Negotiation-A Review. Research Journal of Pharmacy and Technology. 2018;11(8):3727-30.
[8]. Nandakumar M, Nasim I. Comparative evaluation of grape seed and cranberry extracts in preventing enamel erosion: An optical emission spectrometric analysis. J Conserv Dent. 2018 Sep-Oct;21(5):516-520. PubmedPMID: 30294113.

[9]. Blatz MB, Hürzeler MB, Strub JR. Reconstruction of the lost interproximal papilla--presentation of surgical and nonsurgical approaches. Int J Periodontics Restorative Dent. 1999 Aug;19(4):395-406.PubmedPMID:10709507.

[10]. Helvey GA. Closing diastemas and creating artificial gingiva with polymer ceramics. CompendContinEduc Dent. 2002 Nov;23(11):983-6.PubmedPMID: 12526188.

[11]. Aschheim KW, Dale BG. Esthetic Dentistry: A Clinical Approach to Techniques and Materials. Mosby Incorporated; 2001. 606 p.

[12]. Bağiş B, Bağiş YH. PORSELEN LAMINATE VENEERLERIN KLINIKK UYGULAMA AŞAMALARI: KLINIIK BİR OLGU SUNUMU [Internet]. Ankara Üniversitesi Diş Hekimliği Fakültesi Dergisi. 2007;49-57.

[13]. Hussainy SN, Nasim I, Thomas T, Ranjan M. Clinical performance of resinmodified glass ionomer cement, flowable composite, and polyacid-modified resin composite in noncarious cervical lesions: One-year follow-up. J Conserv Dent. 2018 Sep-Oct;21(5):510-515. PubmedPMID: 30294112.

[14]. Teja KV, Ramesh S. Shape optimal and clean more. Saudi Endodontic Journal. 2019 Sep 1;9(3):235.

[15]. Ravinthar K. Recent advancements in laminates and veneers in dentistry. Research Journal of Pharmacy and Technology. 2018;11(2):785-7.

[16]. Prabhu R, Bhaskaran S, Prabhu KRG, Eswaran MA, Phanikrishna G, Deepthi B. Clinical evaluation of direct composite restoration done for midline diastema closure - long-term study [Internet]. J Pharm Bioallied Sci. 2015 Aug;7(Suppl 2):S559-62. PubmedPMID: 26538917.

[17]. Wolff D, Kraus T, Schach C, Pritsch M, Mente J, Staehle HJ, et al. Recontouring teeth and closing diastemas with direct composite buildups: a clinical evaluation of survival and quality parameters. Journal of dentistry. 2010 Dec 1;38(12):1001-9.

[18]. Silvani S, Trivelato RF, Nogueira RD, de Souza Gonçalves L, Geraldo-Martins VR. Factors affecting the placement or replacement of direct restorations in a dental school. Contemporary Clinical Dentistry. 2014 Jan;5(1):54.

[19]. Ramamoorthi S, Nivedhitha MS, Divyanand MJ. Comparative evaluation of postoperative pain after using endodontic needle and EndoActivator during root canal irrigation: A randomised controlled trial. AustEndod J. 2015 Aug;41(2):78-87.PubmedPMID: 25195661.

[20]. Ramanathan S, Solete P. Cone-beam Computed Tomography Evaluation of Root Canal Preparation using Various Rotary Instruments: An in vitro Study. The journal of contemporary dental practice. 2015 Nov 1;16(11):869-72.

[21]. Siddique R, Sureshbabu NM, Somasundaram J, Jacob B, Selvam D. Qualitative and quantitative analysis of precipitate formation following interaction of chlorhexidine with sodium hypochlorite, neem, and tulsi. J Conserv Dent. 2019 Jan;22(1):40-7.PubmedPMID: 30820081.

[22]. Rajakeerthi R, Ms N. Natural Product as the Storage medium for an avulsed tooth-A Systematic Review. Cumhuriyet Dental Journal. 2019;22(2):24956.

[23]. Noor SS, Shihaab SS. Pradeep. Chlorhexidine: Its properties and effects [Internet]. Vol. 9. Research Journal of Pharmacy and Technology. 2016:1755.

[24]. Ramesh S, Teja K, Priya V. Regulation of matrix metalloproteinase-3 gene expression in inflammation: A molecular study [Internet]. Vol. 21, Journal of Conservative Dentistry. 2018. p. 592.

[25]. Janani K, Palanivelu A, Sandhya R. Diagnostic accuracy of dental pulse oximeter with customized sensor holder, thermal test and electric pulp test for the evaluation of pulp vitality: an in vivo study. Brazilian Dental Science. 2020 Jan 31;23(1):8-p.

[26]. Manohar MP, Sharma S. A survey of the knowledge, attitude, and awareness about the principal choice of intracanal medicaments among the general dental practitioners and nonendodontic specialists. Indian Journal of Dental Research. 2018 Nov 1;29(6):716. 